\title{
Media Pembelajaran Interaktif Berbantu Software Lectora inspire
}

\author{
Hamidah Nursidik ${ }^{*}$, Indah Resti Ayuni Suri² \\ 1SMP Abdurrahman Auf. Jalan Ratu Dibalau No.68, Way Kandis, Tj. Senang, Bandar Lampung \\ 35131, Indonesia. \\ 2 Universitas Islam Negeri Raden Intan Lampung. Jalan Endro Suratmin, Sukarame, Bandar \\ Lampung 35133, Indonesia. \\ *Corresponding Author. E-mail: hamidahnursidik@gmail.com
}

Received : 28-05-2018; Revised : 30-05-2018; Accepted : 31-05-2018

\begin{abstract}
Abstrak
Penelitian dan pengembangan ini bertujuan untuk mengetahui kevalidan produk media pembelajaran interaktif berbantu software lectora inspire dan untuk mengetahui respon peserta didik terhadap media pembelajaran interaktif berbantu software lectora inspire pada materi relasi dan fungsi yang telah dikembangkan. Metode dalam penelitian yang digunakan adalah 7 tahap dari 10 tahap metode penelitian dan pengembangan dari Brog and Gall yang telah dimodifikasi oleh sugiyono. Tahap-tahapnya yaitu potensi dan masalah, pengumpulan data, desain produk, validasi, perbaikan desain, uji coba produk, dan revisi produk. Instrument pengumpulan data yang digunakan adalah lembar validasi ahli dan angket respon peserta didik Berdasarkan hasil penelitian menunjukan : Media pembelajaran interaktif berbantu software lectora inspire pada materi relasi dan fungsi kelas X yang dikembangkan dengan Brog and Gall yang dimodifikasi oleh sugiyono dinyatakan layak digunakan oleh ahli materi dan ahli media dengen kriteria baik dengan penilaian rat-rata ahli materi 4,2 dan ahli media 3,5. Respon peserta didik terhadap media pembelajaran interaktif berbantu software lectora inspire pada materi relasi dan fungsi memperoleh kriteria baik dengan nilai rata-rata 4,0167.
\end{abstract}

Kata kunci: Media Pembelajaran Interaktif, Software Lectora inspire, Kelas X

\begin{abstract}
This research and development aims to know the prevalence of interactive learning media products assisted software lectora inspire and to know the response of learners to interactive learning media assisted software lectora inspire on material relations and functions that have been developed. The method used in this research is 7 stages from 10 stages of research and development method from Brog and Gall which have been modified by sugiyono. The stages are potential and problems, data collection, product design, validation, design improvement, product testing, and product revision. Instrument data collection used is validation sheet and questionnaire response of learners. Based on the results of the study showed: Interactive learning media assisted software lectora inspire on material relations and class $X$ functions developed with Brog and Gall modified by sugiyono declared feasible to be used by experts materials and media experts with good criteria with assessment of average material experts 4,2 and the media expert 3,5. Student response to interactive learning media assisted software lectora inspire on material relation and function get good criterion with average value 4,0167.
\end{abstract}

Keywords: Interactive learning media products, Lectora inspire Software

\section{PENDAHULUAN}

Menurut Hamalik dalam buku berjudul "Media Pembelajaran" karya Arsyad (2011) mengemukakan bahwa pemakaian media dalam pembelajaran dapat membangkitkan keingintahuan dan minat baru peserta didik, meningkatkan motivasi dan rangsangan dalam kegiatan belajar, dan bahkan berpengaruh secara psikologis kepada peserta didik. 
Penggunaan media pembelajaran dalam tahap orientasi pembelajaran akan sangat membantu keefektifan proses pembelajaran dan penyampaian pesan dan isi pada saat itu, selain membangkitkan motivasi dan minat peserta didik, media pembelajaran juga dapat membantu peserta didik meningkatkan pemahaman, menyajikan data dengan menarik dan terpercaya, memudahkan penafsiran data dan memadatkan informasi. Penggunaan media pembelajaran dapat membantu pendidik mengatasi keterbatasan penyampaian materi (Linda, Noer, \& Oktavianti, 2016).

Salah satu bahan ajar yang sesuai dan tepat digunakan untuk peserta didik adalah dengan memodifikasi media pembelajaran dalam wahana yang menarik sehingga menumbuhkan rasa cinta terhadap pelajaran matematika (Diyanto et al., 2018). Perkembangan teknologi dalam dunia pendidikan tidak lepas dari ilmu matematika, hanya saja itu semua bertolak belakang dengan peserta didik yang mengagap matematika pelajaran yang sulit (Holidun, Masykur, Suherman, \& Putra, 2018). Media pembelajaran berkembang dari waktu ke waktu, seiring dengan perkembangan teknologi (Shalikhah, Primadewi, \& Iman, 2017).

Berdasarkan penelitian oleh (Siamy, Syazali, \& Farida, 2018) yang mengembangkan media belajar interaktif mendapat hasil sangat menarik dari validator dan respon sangat baik oleh peserta didik. Kehadiran media dalam pembelajaran juga dikatakan dapat membantu peningkatan pemahaman peserta didik, penyajian data atau informasi lebih menarik dan terpercaya, memudahkan penafsiran data dan memadatkan informasi (Astutik \& Rusimamto, 2016). Sesaui dengan penelitian yang dilakukan oleh (Waskito, 2014) yang juga mengembangkan media pembelajaran interaktif yang jika dilihat dari kesimpulan media yang dikembangkan dapat digunakan dengan baik dan dapat dijadikan alat bantu proses pembelajaran, perbedaan yang dilihat dari penelitian yang telah dilakukan dan yang akan dilakukan peneliti yaitu sarana atau media yang digunakan serta materi yang akan disampaikan didalam media.

Berdasarkan penelitian terdahulu di atas dan analisis yang telah dilakukan maka dapat diketahui bahwa pengembangan media pembelajaran terbukti efktif untuk meningkatkan minat belajar peserta didik. Perbedaan penelitian yang telah dengan penelitian yang akan dilakukan oleh peneliti yaitu target objek penelitian dan media yang akan digunakan. Media pembelajaran interaktif telah banyak dikembangkan namun tidak banyak guru menggunakanya dalam kelas.

Media yang akan digunakan peneliti disini yaitu software lectora inspire. Merujuk dari penelitian oleh Zuhri \& Rizaleni (2016) Lectora inspire merupakan software pengembangan belajar elektronik ( $e$-learning) yang relatif mudah diaplikasikan atau diterapkan karena tidak memerlukan pemahaman bahasa pemrograman yang canggih. Pada penelitian yang telah dilakukan media lectora inspire mempunyai potensi besar untuk meningkatkan motivasi belajar peserta didik dibandingkan pembelajaran konvensional. Selain itu penelitian oleh Wiyono (2015) dengan menggunakan lectora inspire penelitian memperoleh hasil bahwa media terbukti valid, praktis dan efektif meningkatkan hasil belajar peserta didik. Pembelajaran menggunakan media pembelajaran berbantu softwere lectora inspire efektif dilakukan untuk meningkatkan hasil belajar peserta didik (Astutik \& Rusimamto, 2016).

Merujuk dari pemaparan tentang lectora inspire oleh peneliti terdahulu penulis menyimpulkan bahwa lectora 
Desimal, 1 (2), 2018 - 239

Hamidah Nursidik, Indah Resti Ayuni Suri

inspire memiliki potensi besar yang efektif meningkatkan hasil belajar peserta didik yang mana persamaan yang akan dialkukan yaitu media yang akan dipakai dan perbedaannya yaitu target objek penelitian serta materi yang akan dikembangkan.

\section{METODE}

Jenis penelitian ini adalah penelitian dan pengembangan. Dalam penelitian dan pengembangan ini menggunakan metode Reserch and Development (Sugiyono, 2013). Penelitian dan pengembangan ini menggunakan metode (R\&D) Reserch and Development, dengan memanfaatkan media pembelajaran komputer sebagai media pembelajaran, yang tujuannya untuk menghasilkan sebuah media pembelajaran yang berbentuk media interaktif, dimana didalamnya berisikan tutorial pemebelajaran dan soal-soal evaluasi (Hakim \& Haryudo, 2014).

Pada penelitian ini dikembangkan media pembelajaran yang bersifat interaktif. Subjek uji coba dalam penelitian ini adalah peserta didik kelas $\mathrm{X}$ SMA Negeri 8 Bandar Lampung. Pengembangan dilakasanakan pada mata pelajaran matematika dengan pokok bahasan "Relasi dan Fungsi".

Penelitaian ini mengacu pada Model Brog dan Gall, model ini meliputi : 1) Potensi dan masalah, 2) Pengumpulan data, 3) Desain Produk 4) Validasi desain, 5) Perbaikan Desain, 6) Uji coba Produk, 7) Revisi Produk, 8) Uji Pelaksanaan Lapangan, 9) Penyempurnaan Produk Akhir, 10) Dimensi dan Implementasi, dari model Brog dan Gall ini kemudian yang dikembangakan (Sugiyono, 2016).

Langkah tersebut dapat disesuaikan dengan kebutuhan, peneliti. Dengan demikian langkah-langkah penggunaan Research and Development (R\&D) dibatasi sebagai berikut :

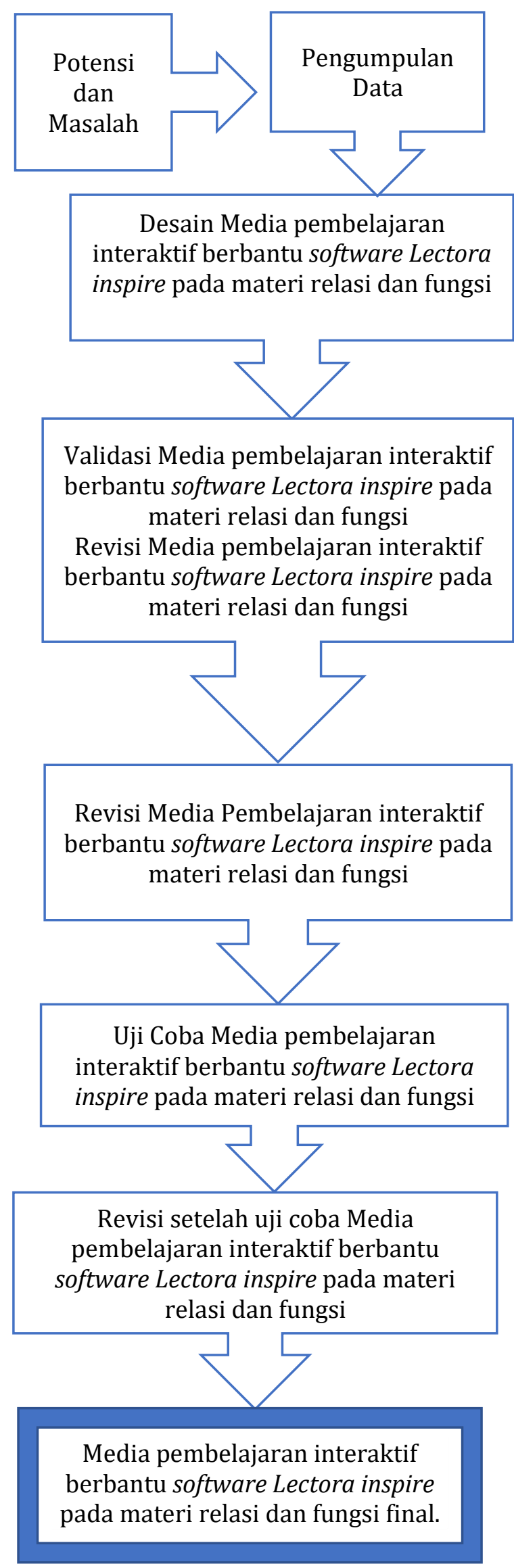

Gambar 1. Tahapan Pengembangan 
Sedangkan rumus untuk menentukan interval adalah sebagai berikut (Eko Yulianto \& Eli Rohaeti, 2013).

$$
\text { Skor rata }- \text { rata }=\frac{\text { jumlah Skor }}{\text { jumlah Butir }}
$$

\section{HASIL DAN PEMBAHASAN}

Penelitian ini menghasilkan sebuah produk berupa media pembelajaran interaktif berbantu software lectora inspire, penelitian ini dikembangkan menggunakan prosedur penelitian dan pengembangan (Brog and Gall.) Data hasil setiap tahapan yaitu pertama potensi dan masalah dari hasil observasi awal didapat hasil bahwa dalam proses belajar mengajar belum memanfaatkan fasilitas sekolah seperti wifi, proyektor dan lab komputer yang mana bisa dimanfaatkan sebagai sarana tambahan sumber belajar, selain itu didapat fakta bahwa tidak semua peserta didik memenuhi standar KKM khususnya pada materi relasi dan fungsi.

Tahap selanjutnya yaitu pengumpulan data, mengumpulkan sumber referensi seperti jurnal-jurnal matematika yang berkaitan dengan media pembelajaran interaktif yang berbantu software lectora inspire pada materi relasi dan fungsi kelas $\mathrm{X}$ dan buku matematika kelas X kurikulum 2013.

Setelah data terkumul dilanjutkan mendesain produk media pembelajaranya. Desain produk pengembangan media pembelajaran interaktif yang berbantu software lectora inspire pada materi relasi dan fungsi kelas $\mathrm{X}$ terdiri dari kompetensi, materi, latihan soal, penulis, pustaka dan evaluasi. Dilanjutkan validasi Desain, validasi dilakukan oleh ahli materi dan ahli media

\section{a. Validasi Ahli materi}

Validasi ahli materi bertujuan untuk menguji kelengkapan materi, kebenaran materi, dan sistematika materi, dilakukan dalam 2 tahap. Diperoleh hasil bahwa media pembelajaran layak dan siap digunakan dengan kriteria "Baik", dapat dilihat pada Tabel 1

Tabel 1. Hasil Ahli Materi

\begin{tabular}{ccc}
\hline Skor Rata-rata & Kriteria & Keterangan \\
4,2 & Baik & Tidak Revisi \\
\hline
\end{tabular}

\section{b. Validasi Ahli Media}

Validasi ahli media bertujuan untuk menguji kemenarikan dan penyajian pada media pembelajaran, dilakukan dalam 2 tahap. Diperoleh hasil bahwa media pembelajaran layak dan siap digunakan dengan kriteria "Baaik", dapat dilihat pada Tabel 2 .

Tabel 2. Hasil Ahli Media

\begin{tabular}{ccc}
\hline Skor Rata-rata & Kriteria & Keterangan \\
3,5 & Baik & Tidak Revisi \\
\hline
\end{tabular}

Setelah desain produk divalidasi melalui penilaian ahli materi, dan ahli media, peneliti melakukan revisi terhadap desain produk yang dikembangkan berdasarkan masukanmasukan ahli tersebut.

a. Revis Ahli Materi

Berikut ini tampilan yang harus diperbaiki setelah mendapat saran dari validator :

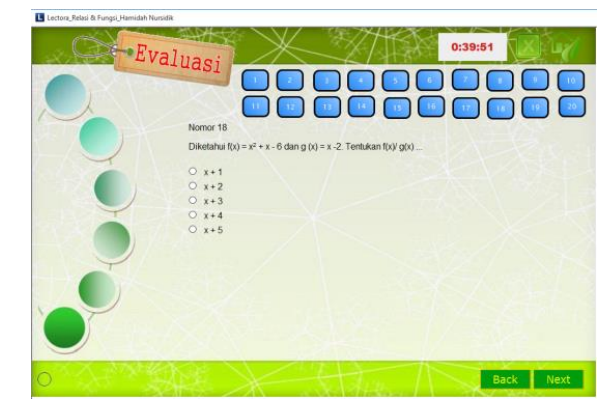

Gambar 2. Tampilan Penggunaan Equation Sebelum Revisi

Tampilan pada Gambar 2 merupakan tampilan awal sebelum revisi, tampilan tersebut menurut 
Desimal, 1 (2), 2018 - 241

Hamidah Nursidik, Indah Resti Ayuni Suri

ahli materi harus diperbaiki karena penulisan rumus tidak menggunakan equation, saran validator untuk menggunakan equationpada penulisan setiap rumus matematika pada media.

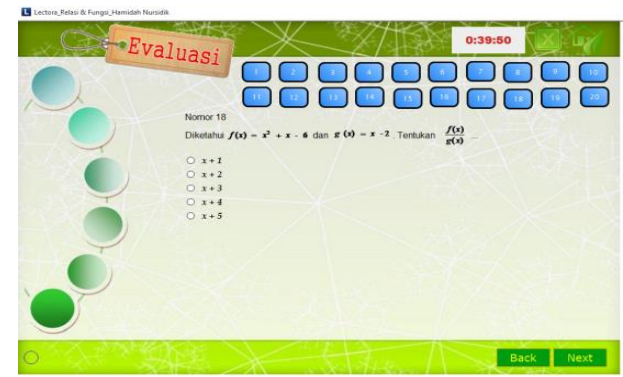

Gambar 3. Tampilan Penggunaan Equation Setelah Revisi

Gambar 3 merupakan tampilan media setelah dilakukanya revisi. Tampilan tersebut sudah baik karena sudah menggunakan equation pada penulisan setiap rumusnya.

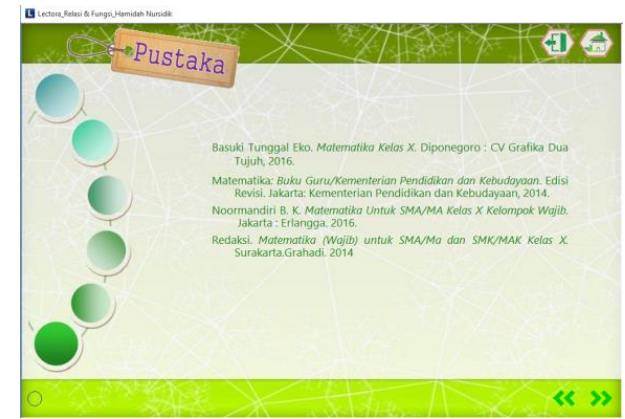

Gambar 4. Tampilan Penambahan Buku Referensi Sebelum Revisi

Gambar 4 di atas merupakan tampilan awal daftar pustaka pada media, setelah mendapat masukan dari validator agar menambah buku referensi yang dipakai.

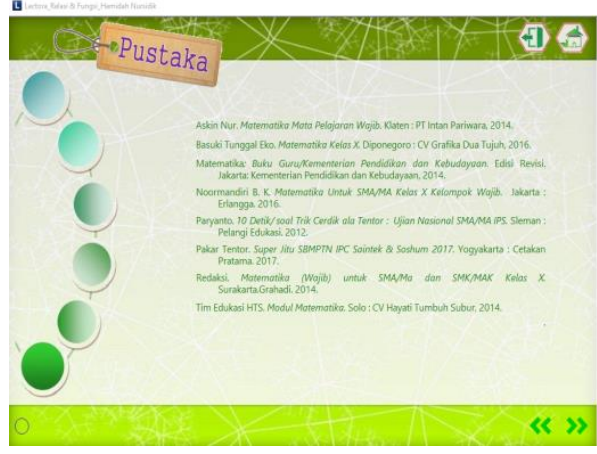

Gambar 5. Tampilan

Penambahan Buku Referensi Setelah Revisi

Gambar 5 merupakan tampilan daftar pustaka setelah dilakukkanya revisi untuk menambahkan buku referensi yang dipakai.

b. Revisi Ahli Media

Berikut ini tampilan yang harus diperbaiki setelah mendapat saran dari validator :

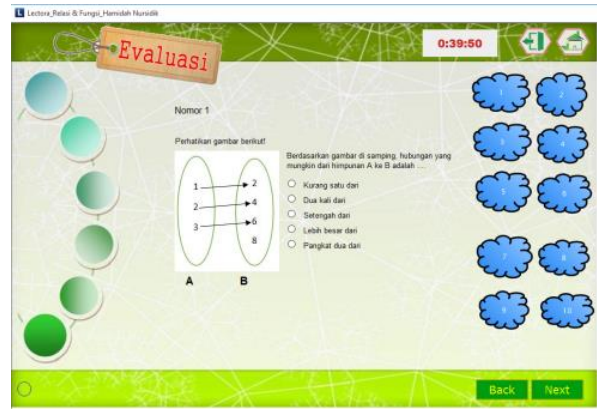

Gambar 6. Tampilan Awal

Penggunaan Tombol Evaluasi

Tampilan pada Gambar 6 di atas merupakan tampilan penggunaan tombol sebelum revisi. Dimana penggunaan tomol kurang maksimal dan perlu adanya penambahan tombol untuk digunakan. 
Desimal, 1 (2), 2018 - 242

Hamidah Nursidik, Indah Resti Ayuni Suri

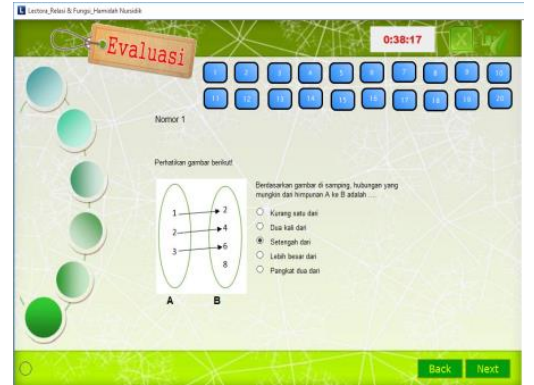

Gambar 7. Tampilan Penggunaan setelah Revisi

Gambar 7 merupakan tampilan penggunaan tombol pada menu evaluasi setelah diperbaik.

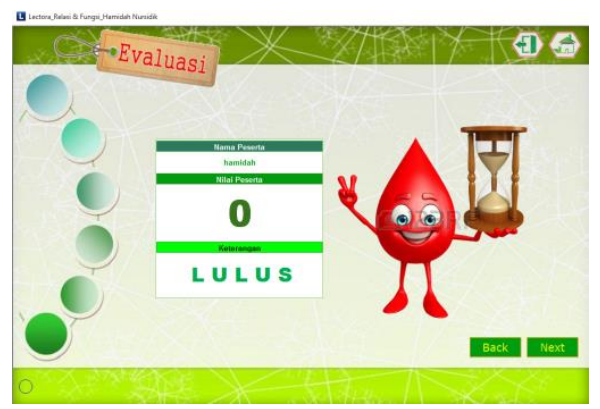

Gambar 8. Tampilan Awal Hasil Penilaian

Gambar 8 merupakan tampilan awal hasil penilaian sebelum dilakukannya revis dimana dari Gambar 8 terlihat bahwa tampilan hasil belum maksimal dimana hasil angka 0 akan tetapi keterangan lulus.

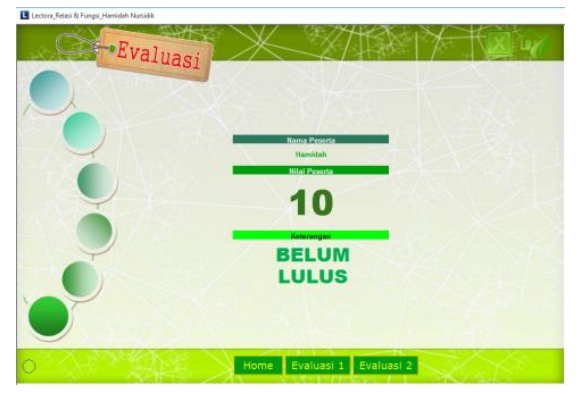

\section{Gambar 9. Tampilan Hasil \\ Penilaian Setelah Revisi}

Gambar 9 merupakan tampilan hasil penilaian setelah dialkukanya revisi atas saran dari validator untuk menyeimbangkan angka dan ketrangan.
Selanjutnya setelah dilakukan perbaikan desain dan dinyatakan valid maka dilakukan uji coba produk. Hasil uji coba terkait kemenarikan dilakukan melalui dua tahapan yaitu uji kelompok kecil dan uji lapangan mengalami peningkatan rata-rata skor pada aspeknya, perbandingan hasil uji coba dapat dilihat juga pada Tabel 3.

Tabel 3. Hasil Uji Coba Kelompok Kecil

\begin{tabular}{cccc} 
Responden & $\begin{array}{c}\text { Jumlah } \\
\text { Skor }\end{array}$ & $\begin{array}{c}\text { Skor } \\
\text { Kelayakan }\end{array}$ & Kriteria \\
1 & 35 & 3.5 & $\mathrm{~B}$ \\
2 & 31 & 3.1 & $\mathrm{~B}$ \\
3 & 30 & 3.0 & $\mathrm{C}$ \\
4 & 36 & 3.6 & $\mathrm{~B}$ \\
5 & 39 & 3.9 & $\mathrm{~B}$ \\
6 & 33 & 3.3 & $\mathrm{C}$ \\
7 & 45 & 4.5 & $\mathrm{SB}$ \\
8 & 36 & 3.6 & $\mathrm{~B}$ \\
9 & 29 & 2.9 & $\mathrm{C}$ \\
10 & 39 & 3.9 & $\mathrm{~B}$ \\
Jumlah & 352 & 3.92 & $\bar{x}=3.92$ \\
\hline
\end{tabular}

Tabel 3 menunjukan hasil dari uji coba kelompok kecil yang di ujikan kepada 10 peserta didik dengan perolehan angka 3,92 dengan kriteria "Baik". Dari perolehan tersebut maka media dinyatakan baik digunakan sehingga tidak ada revisi kembali dan bisa dilanjutkan ke uji coba kelompok besar. Tabel uji coba kelompok besar bisa dilihat pada Tabel 4. 
Desimal, 1 (2), 2018 - 243

Hamidah Nursidik, Indah Resti Ayuni Suri

Tabel 4. Hasil Uji Coba Kelompok Besar

\begin{tabular}{cccc}
\hline Responden & $\begin{array}{c}\text { Jumlah } \\
\text { Skor }\end{array}$ & $\begin{array}{c}\text { Skor } \\
\text { Kelayakan }\end{array}$ & Kriteria \\
1 & 34 & 3.4 & $\mathrm{C}$ \\
2 & 35 & 3.5 & $\mathrm{~B}$ \\
3 & 34 & 3.4 & $\mathrm{C}$ \\
4 & 40 & 4.0 & $\mathrm{~B}$ \\
5 & 28 & 2.8 & $\mathrm{C}$ \\
6 & 31 & 3.1 & $\mathrm{C}$ \\
7 & 42 & 4.2 & $\mathrm{~B}$ \\
8 & 31 & 3.1 & $\mathrm{C}$ \\
9 & 35 & 3.5 & $\mathrm{~B}$ \\
10 & 33 & 3.3 & $\mathrm{C}$ \\
11 & 32 & 3.2 & $\mathrm{C}$ \\
12 & 39 & 3.9 & $\mathrm{~B}$ \\
13 & 35 & 3.5 & $\mathrm{~B}$ \\
14 & 36 & 3.6 & $\mathrm{~B}$ \\
15 & 40 & 4.0 & $\mathrm{~B}$ \\
16 & 31 & 4.1 & $\mathrm{~B}$ \\
17 & 45 & 4.5 & $\mathrm{SB}$ \\
18 & 45 & 4.5 & $\mathrm{SB}$ \\
19 & 44 & 4.4 & $\mathrm{SB}$ \\
20 & 45 & 4.5 & $\mathrm{SB}$ \\
21 & 40 & 4.0 & $\mathrm{~B}$ \\
22 & 35 & 3.5 & $\mathrm{~B}$ \\
23 & 28 & 2.8 & $\mathrm{C}$ \\
24 & 35 & 3.5 & $\mathrm{~B}$ \\
Jumlah & 873 & 4.04167 & $\bar{x}=4.04167$ \\
\hline & & &
\end{tabular}

Tabel 4 menunjukan hasil dari uji coba kelompok besar yang di ujikan kepada 24 peserta didik dengan perolehan angka 4,01 dengan kriteria "Baik". Baik disini menunjukan bahwa media pembelajaran interaktif yang dikembangkan layak digunakan dan terbukti valid, praktis dan efektif.

Setelah dilakukan uji coba kelompok kecil dan uji coba kelompok besar untuk mengetahui kemenarikan media pembelajaran berbantu software lectora inspire pada materi relasi dan fungsi, produk dikatakan kemenarikanya baik sehingga tidak dilakukan uji coba ulang. Selanjutnya media pembelajaran dapat dimanfaatkan sebagai salah satu media belajar bagi peserta didik dan pendidik di SMA pada materi relasi dan fungsi kelas X.

Penelitian ini sama dengan penelitian sebelumnya bahwa media pembelajaran interaktif berbantu software lectora inspire menunjukan hasil yang positif, valid, praktis dan efektif
(Wiyono, 2015), analisi data dari validator menyatakan bahwa media dalam kategori sangat layak digunakan dalam pembelajaran (Zuhri \& Rizaleni, 2016). Hasil kelayakan produk mendapat kriteria sangat layak dan respon peserta didik sangat baik (Astutik \& Rusimamto, 2016), media pembelajaran yang dihasilkan layak digunakan sebagai media pembelajaran (Ismaili \& Asto, 2017). Media pembelajaran interaktif berbantu software lectora inspire yang telah dikembangkan oleh peneliti memiliki kesamaan dengan penelitian yang telah dilakukan oleh peneliti di atas yang diambil dari kesimpulannya bahwa media yang dikembangkan oleh peneliti juga layak digunakan dan mendapat respon yang baik dari peserta didik. Sehingga dari pemaparan analisis di atas kesimpulan peneliti bahwa perlu adanya pengembangan- pengembangan media pembelajaran sehingga nanti diharapkan bisa meningkatkan kemampuan maupun motivasi belajar matematika peserta didik.

\section{SIMPULAN DAN SARAN}

Kesimpulan yang diperoleh dari penelitian dan pengembangan ini adalah media pembelajaran interaktif berbantu software lectora inspire yang dikembangkan dengan Brog and Gall yang dimodifikasi oleh sugiyono dinyatakan layak oleh ahli materi dan ahli media. Ditinjau dari respon peerta didik terhadap media pembelajaran interaktif yang dikembangkan memperoleh kriteria "Baik".

Berdasarkan kesimpulan diatas maka penulis menyarankan kepada peneliti lain agar dapat mengembangkan media pembelajaran interaktif berbantu software lectora inspire pada materi lain dan diharapkan kepada peneliti lain agar dapat dikembangkan media lain dengan materi relasi dan fungsi. 
Desimal, 1 (2), 2018 - 244

Hamidah Nursidik, Indah Resti Ayuni Suri

\section{DAFTAR PUSTAKA}

Arsyad, A. (2011). Media Pembelajaran. Jakarta: Rajagrafindo.

Astutik, M., \& Rusimamto, P. W. (2016). Pengembangan Media Pembelajaran Multimedia Interaktif Berbantuan Software Lectora Inspire untuk Meningkatkan Hasil Belajar pada Mata Pelajaran Teknik Listrik di SMK Negeri 2 Surabaya. Jurnal Pendidikan Teknik Elektro, 5(1), 107-114.

Diyanto, R., Dwi, F., Nasution, S. P., Anggoro, B. S., English, B. S., Islam, U., Komputer, P. B. (2018). Multimedia Pembelajaran Matematika Interaktif Berbasis Komputer. Desimal: Jurnal Matematika, 1(2), 191-199.

Hakim, B. R., \& Haryudo, S. I. (2014). Pengembangan Media Pembelajaran Interaktif Animasi Flash pada Standar Kompetensi Memasang Instalasi Penerangan Listrik Bangunan Sederhana di SMK Walisongo 2 Gempol. Jurnal Pendidikan Teknik Elektro, 3(1), 1521.

Holidun, Masykur, R., Suherman, \& Putra, F. G. (2018). Kemampuan Pemecahan Masalah Matematis Kelompok Matematika Ilmu Alam dan IlmuIlmu Sosial. Al-Jabar: Jurnal Pendidikan Matematika, 1(1), 30.

Ismaili \& Asto. (2017). Pengembangan Media Pembelajaran Menggunakan Multimedia Interaktif Lectora Inspire pada Kompetensi Dasar Menerapkan Macam- Elektronika Dasar Di Smk Negeri 2 Surabaya. Jurnal Pendidikan Teknik Elektro, 6(3), 219-223.

Linda, R., Noer, A. M., \& Oktavianti, N. A. (2016). Development of Lectora Inspire as Interactive Multimedia Chemistry Learning in Senior High School. Jurnal Pendidikan Kimia, 8(3), 188-196.

Shalikhah, N. D., Primadewi, A., \& Iman, M. S. (2017). Media Pembelajaran Interaktif Lectora Inspire Sebagai Inovasi Pembelajaran. Media
Pembelajaran Interaktif Lectora Inspire Sebagai Inovasi Pembelajaran, 20(1), 9-16.

Siamy, L., Syazali, M., \& Farida. (2018). Media Belajar Matematika Berbasis Multimedia Interaktif dengan Pendekatan Contextual Teaching and Learning. Desimal: Jurnal Matematika, 1(1), 113-117.

Sugiyono. (2013). Metode Penelitian Pendidikan. Bandung: Alfabeta.

Sugiyono. (2016). Metode Penelitian Adminitrasi Dilengkapi dengan Metode R \& D. Bandung: Alpabeta.

Waskito, D. (2014). Media Pembelajaran Interaktif Matematika bagi Sekolah Dasar Kelas 6 Berbasis Multimedia. Speed Journal - Sentra Penelitian Engineering Dan Edukasi, 11(3), 5965.

Wiyono, K. (2015). Pengembangan Multimedia Interaktif Pembelajaran Teori Kinetik Gas Berbantuan Lectora Inspire untuk Siswa Sekolah Menengah Atas (SMA). Jurnal Inovasi Dan Pembelajaran Fisika, 2(2), 211219.

Zuhri, M. S., \& Rizaleni, E. A. (2016). Pengembangan Media Lectora Inspire dengan Pendekatan Kontekstual pada Siswa SMA Kelas X. Jurnal Inovasi Dan Pembelajaran Fisika, 5(2), 113-119. 